The original publication is available at www.springerlink.com

Labusch, N., Koebele, F., Aier, S., Winter, R.: The Architects' Perspective on Enterprise Transformation: An Explorative Study, Harmsen, F., Proper, H. (Eds.): Practice-driven driven Research on Enterprise Transformation (PRET-6), Utrecht, The Netherlands, 06.06.2013, Springer, Berlin Heidelberg, LNBIP 151, 2013, pp. 106-124., http://link.springer.com/chapter/10.1007/978-3-642-38774-6_8

\title{
The Architects' Perspective on Enterprise Transformation: An Explorative Study
}

\author{
Nils Labusch ${ }^{1}$, Felix Koebele ${ }^{2}$, Stephan Aier ${ }^{1}$, Robert Winter ${ }^{1}$ \\ ${ }^{1}$ Institute of Information Management, University of St.Gallen, St.Gallen, \\ Switzerland \\ \{Nils.Labusch, Stephan.Aier, Robert.Winter\}@unisg.ch \\ ${ }^{2}$ Institute of Information Management, University of St.Gallen, St.Gallen, \\ Switzerland \\ Felix@Koebele.ch
}

\begin{abstract}
.
Enterprise architecture management (EAM) is considered to be a valuable means in order to support large-scale changes, called enterprise transformations (ET). In the study at hand we apply an explorative qualitative approach in order to investigate the potentials of EAM to support ETs by discussing the topic with highly knowledgeable informants that deal with EAM on a daily basis in nine different companies. The results reveal six propositions about the current and future state of EAM as an ET supporting discipline. The propositions reveal a distinction between IT and business focused EAM, means and activities taken by EAM to support ET, major pitfalls that need to be avoided as much as perceptions about the future of the discipline.
\end{abstract}

Keywords: enterprise transformation, enterprise architecture management, empirical study

\section{Introduction}

Enterprise architecture (EA) is the definition and representation of a high-level view of an enterprise's (company, governmental body, etc.) business processes and IT systems, their interrelationships, and the extent to which these processes and systems are shared by different parts of this enterprise [1]. Enterprise architecture management (EAM) is a tool to establish an EA by describing the current state of the organizations' structure and developing a strategy, and thus a desired future state of the enterprise [2]. The transition between these two states is called enterprise transformation (ET) $[3,4]$. ET is an "extensive, fundamental modification of the company, which is generally initiated by strategic decisions made by the management" [5].

The activities that are necessary in such transformation processes need to be coordinated in an organized manner [6]. Coordination is considered as the management of dependencies between activities [7]. The involved activities will typically consider 
several additional aspects of the enterprise, such as human resourcing, finance, or reporting structures [4].

EAM is seen by many scholars as a means to support the coordination of transformation $[8,9,10,11]$. However, in many transformations, architects are not involved or limited to a support of IT matters [12]. Therefore, we are interested in the reasons for such limitations - how do architects see their role in transformations, which perspective do they take, what is the scope they consider? Summarized the following research question guides our explorative study:

RQ: How do enterprise architects perceive enterprise transformations and how do they contribute to the successful management of these.

In the following section we present related work concerning the topic area. We continue with presenting our research approach. In section four we describe the results by providing the qualitative data that we collected. We go on with a discussion and provide summary and limitations in the last section.

\section{Related Work}

\subsection{Enterprise Transformation}

ET is a company's response to the dynamics of their environment or to internal crisis. Because of this oftentimes radical and fast moving environment, organizations need to establish the ability to react even faster to these sometimes fundamental changes [13]. ET does not focus the minor changes a company undergoes in their strategic considerations or processes every day, but describes the fundamental changes that substantially modify its relationships to internal and external stakeholders [14].

According to Rouse [14] four main causes for transformations exist: First, the revenue opportunities of emerging markets or new technologies are initiators of transformations. For example the rise of mobile applications has completely changed some businesses and value proposition of companies, which made it necessary to transform their processes, technologies and strategy [15]. Second, threats of the market or technology changes are causing ETs [14]. Third, transformation initiatives by main competitors drive ETs. Sometimes changes in the environment become only visible if a major competitor adapts itself and suddenly performs better or attracts more or different customers [14]. Finally, internal crisis within the enterprise fosters ETs. Examples are a decrease of key performance indicators such as cash flow or market performance [14].

Management of ET includes manifold activities that need to be coordinated. Kotnour et al. [16] identify four major management steps: (1) recognizing the change, (2) establishing an overall philosophy, (3) deciding on future environments and (4) defining the interconnected accountabilities. Uhl \& Gollenia [17] provide an approach that integrates existing disciplines like business process management, IT management, value management, strategy management, project management and others by a newly 
introduced discipline called meta-management. This discipline deals with the coordination and general setup of the transformation [18].

\subsection{Architectural Support of Enterprise Transformation}

The management of EA is a "continuous and iterative management function" [19], meaning that planning and executing EAM is not a one-time effort but requires constant support [20].

One of the main goals of EAM is the continuous alignment of business and IT [13, $19,21]$ in order to improve the performance of the organization. Alignment is supported by creating a holistic and integrated view of the strategy, processes, technology resources and information flows often represented in the different layers of an EA framework [22]. It is a key objective to reduce organizational complexity by codifying and understanding its structures [23]. Ross et al. [9] found that the introduction of EAM enables the reduction of IT costs. This is possible because of a consistent, strategic IT planning [21] which can reduce costs of IT operations as well as application maintenance [24]. Beyond cost reduction, IT responsiveness and flexibility can be increased with a reduced development time of applications, minimized overhead and the ability to reuse IT-components [25].

On the business side, enterprise architecture is supposed to improve risk management, optimize business processes and support decisions [9]. This is possible because EAM is considered to combine and integrate the strategy, business and technology perspective in order to model different future operation scenarios [22].

The type of information that EAM can provide is documented and formalized in manifold meta-models [26, 27, 28, 29]. In [30] we consolidated concepts of those meta-models in order to get an overview about information that is potentially provided by current EAM approaches. Figure 1 illustrates common information objects of EAM.

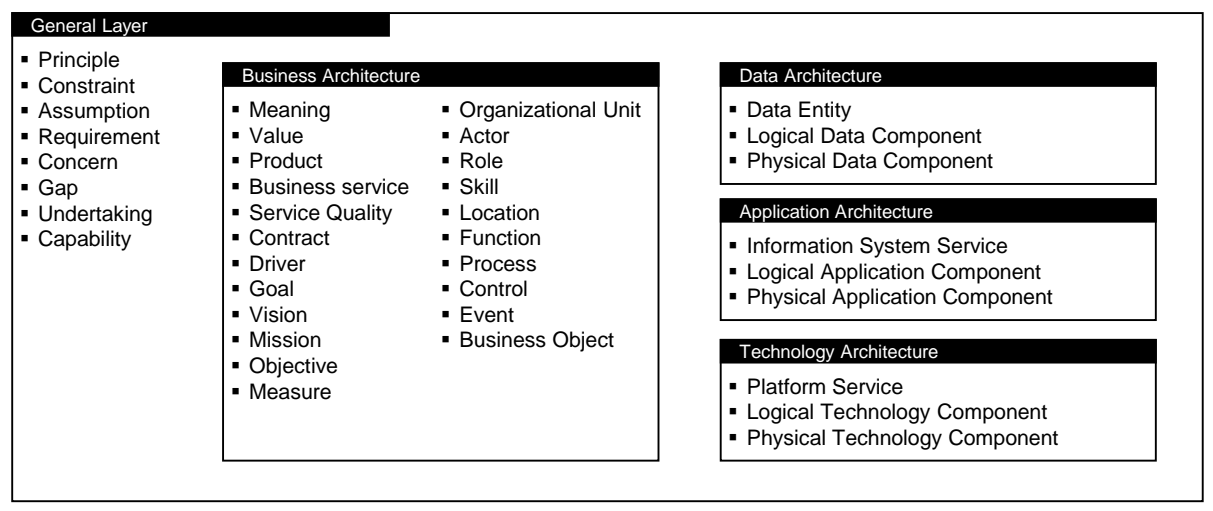

Fig. 1. Information provided by EAM [30]

Asfaw et al. [12] provide a discussion about how EAM is supporting ETs. They identify success factors like communications, stakeholder involvement and guided appli- 
cation development. However, the authors conclude that architecture cannot deal with all occurring challenges. Additional disciplines like change management are needed. Winter et al. [31] illustrate how EAM and ET management differ and what both have in common. Especially the to-be designs and change project roadmaps that EAM creates, are seen as an integrated implementation component and input for ET.

However, almost none of the current literature provides an overview of the architects' perception and opinion about the future support of transformation. Thus, we aim at discussing the current transformation support of EAM and its future evolution.

\section{Research Approach}

We conducted a multiple case study approach guided by the one described by Eisenhardt [32]. Such an approach usually yields more robust and generalizable findings than single case discussions [33].

\subsection{Data Collection}

In order to gain insight to the context of ET and EAM, we conducted a literature search by following guidelines provided by vom Brocke et al. [34] and Webster \& Watson [35]. Since on the one hand we wanted to understand the relation of ET and EAM ahead of the interview phase but on the other hand needed to deal with a huge amount of available sources in the topic area, we concentrated on major journals (Jourqual ranking [36]) and conferences (ECIS, ICIS) by applying the keywords "Enterprise Architecture" OR "Enterprise Architecture Management" on the title. For the ET part we applied the keywords "Enterprise Transformation" OR "change" OR "strategic transformation" OR "IT transformation".

In addition to the structured search, we conducted reverse searches by surveying the references of articles we found during the first search steps. We further added sources that were already known in the research group in order to provide a rich foundation for the preparation of the interviews.

Based on the surveyed literature, we developed the questionnaire for the interviews. The questionnaire consists of four major sections. In Section A we intended to "break the ice" by starting with biographical questions like the informant's job description or company. We move on with questions that aim at understanding the role of EA for the company. The third part deals with ET as such by asking the informant about transformations where he or she was involved in. We related the subsequent questions to these examples. We asked primarily about the extent, the scope and the success of the transformation. In the fourth part of the questionnaire, we asked about the EAM involvement in the described ET example.

In general, we adopted the research approach described in [37]. Thus, we conducted the interviews face-to-face or on the telephone, depending on the availability of the interviewees or the local distance. For the phone interviews we incorporated guidelines given by Burke \& Miller [38] like providing the questionnaire upfront or being aware of the difficulties of the communication channel. We relied on additional data 
sources like reports offered by the companies (e.g. the annual reports), publically available information about the interviewees (e.g. social network profiles), press releases, websites, field notes etc. The triangulation of such sources increases the robustness of the resulting findings [39]. Our informants were all experienced enterprise architects or employed in similar positions like data architect or business architect. We identified the informants by applying the search terms "Enterprise Architect" or "Transformation Architect" in social business networks (Xing and LinkedIn). Our search revealed 86 potential informants in the German speaking area; we could make appointments for interviews with nine of them. All interviews were recorded and transcribed in order to allow for further processing in the research team. We transcribed the interview in the language we discussed with participants. Extracts presented in this paper are translated for understandability reasons. We asked the informants to focus on their own experiences and tried to find examples that are not located too far away in the past. Whenever possible we used court-room questioning in order to avoid questioning that allows informants to speculate [40]. We further promised our informants to keep their and their company's anonymity in order to allow them for providing honest answers.

\subsection{Informants \& Data Analysis}

Our informants were working with nine European companies in different industries. All companies have more than 5000 employees and dedicated EA departments. In Total we recorded and transcribed more than seven hours of interview material. Table 1 provides an overview of the companies and informants.

Table 1. Interview Partners

\begin{tabular}{lll}
\hline Company & Industry & Informant \\
\hline A & Telecom & Head of IT Strategy \& Architecture \\
\hline B & Automotive & Enterprise Architect \\
\hline C & Consulting & Enterprise Business Architect \\
\hline D & Consumer & Enterprise Architect BI and Data \\
\hline E & Banking & Transformation Manager \\
\hline F & Consumer & Lead Enterprise Architect \\
\hline G & Telecom & Enterprise Architect \\
\hline H & Banking & Enterprise Architect \\
\hline I & Banking & Director Integration Architecture \\
\hline
\end{tabular}

We followed recommendations for multiple case studies by Eisenhardt [32] and used within-case and cross case analysis. This implies to understand the interviews and cases conducted in one Company first and afterwards identify commonalities and differences. We used the software ATLAS.ti in order to conduct a first open coding. 
We used the graphical functions of ATLAS.ti in order to cluster the codes in a purposeful way based on semantic similarity [41] to get an overview concerning emerging constructs.

\section{$4 \quad$ Results}

We identified six major constructs that are influencing the current and future support of EAM for ET. These are the ET scenario, EAM activities, EAM artifacts, knowledge about the establishment of EAM as an ET support discipline, pitfalls and perceptions about the future.

\subsection{Enterprise Transformation Scenarios}

We discussed with our informants what they perceive as an ET scenario and ask them to provide concrete examples from their point of view. In Table 2 we summarize the examples given during the study.

Table 2. Transformations Described in the Cases

\begin{tabular}{|c|c|c|c|c|}
\hline Company & Scenario & Goal & Cause & Success \\
\hline A & $\begin{array}{l}\text { Replacement of } \\
\text { IT }\end{array}$ & $\begin{array}{l}\text { Develop a complete } \\
\text { new IT Stack }\end{array}$ & $\begin{array}{l}\text { Merging of mobile and } \\
\text { fixed phone }\end{array}$ & Yes \\
\hline A & Partnerships & $\begin{array}{l}\text { Partnership with exter- } \\
\text { nal companies }\end{array}$ & Changed customer demand & Yes \\
\hline A & $\begin{array}{l}\text { Business pro- } \\
\text { cess reengi- } \\
\text { neering }\end{array}$ & Designing of Services & $\begin{array}{l}\text { Competitor situation de- } \\
\text { mand more flexible prod- } \\
\text { ucts }\end{array}$ & Yes \\
\hline B & $\begin{array}{l}\text { Post-merger } \\
\text { integration }\end{array}$ & $\begin{array}{l}\text { Integration of an Asian } \\
\text { Development Facility }\end{array}$ & Step into Asian market & No \\
\hline B & $\begin{array}{l}\text { Compliance } \\
\text { policies en- } \\
\text { forcement }\end{array}$ & $\begin{array}{l}\text { Roll out of Enterprise } \\
\text { Application Manage- } \\
\text { ment. }\end{array}$ & N/A & No \\
\hline $\mathrm{C}$ & $\begin{array}{l}\text { Replacement of } \\
\text { IT }\end{array}$ & $\begin{array}{l}\text { Companywide auditing } \\
\text { standard }\end{array}$ & $\begin{array}{l}\text { International customers } \\
\text { and stronger competitors }\end{array}$ & Yes \\
\hline $\mathrm{D}$ & $\begin{array}{l}\text { Compliance } \\
\text { policies en- } \\
\text { forcement }\end{array}$ & $\begin{array}{l}\text { Restructuring of IT } \\
\text { demand process }\end{array}$ & $\begin{array}{l}\text { Number of unnecessary } \\
\text { projects }\end{array}$ & Yes \\
\hline IS cc & solidation & $\begin{array}{l}\text { Customer support } \\
\text { services }\end{array}$ & $\begin{array}{l}\text { Old systems and new SAP } \\
\text { system for other areas }\end{array}$ & Yes \\
\hline \multicolumn{2}{|c|}{ IS consolidation } & $\begin{array}{l}\text { Reduce number of } \\
\text { systems }\end{array}$ & Personal changes & Yes \\
\hline
\end{tabular}




\begin{tabular}{llllc}
\hline E & Replacement of IT & $\begin{array}{l}\text { One core banking } \\
\text { system for the group }\end{array}$ & Need to decrease costs & No \\
\hline E & $\begin{array}{l}\text { Post-merger integra- } \\
\text { tion }\end{array}$ & $\begin{array}{l}\text { Acquisition of another } \\
\text { bank }\end{array}$ & --- & Yes \\
\hline F & $\begin{array}{l}\text { New business de- } \\
\text { velopment }\end{array}$ & $\begin{array}{l}\text { Establishment of an } \\
\text { online channel }\end{array}$ & Competitor situation & Yes \\
\hline G & $\begin{array}{l}\text { Post-merger integra- } \\
\text { tion }\end{array}$ & $\begin{array}{l}\text { Integration of the two } \\
\text { IS stacks }\end{array}$ & $\begin{array}{l}\text { Merging of mobile and fixed } \\
\text { phone }\end{array}$ & Yes \\
\hline H & Replacement of IT & $\begin{array}{l}\text { New Access and Iden- } \\
\text { tity Management }\end{array}$ & Regulatory & Yes \\
\hline I & Replacement of IT & $\begin{array}{l}\text { New System for In- } \\
\text { vestment banking }\end{array}$ & Need to reduce costs & No \\
\hline I & IS consolidation & $\begin{array}{l}\text { Consolidation in In- } \\
\text { vestment banking }\end{array}$ & Organizational restructuring & Yes \\
\hline
\end{tabular}

Thus, our informants provided experiences from 16 ETs. Certain scenarios are more similar to each other than other ones. A pretty common scenario is the post-merger integration. Mergers and acquisitions (M\&A) are strategic moves to enhance the growth of the company [42]. The goal is to create synergy effects by "integrating two separate business entities" [43]. Two-third of all mergers fail or do not deliver the expected operational improvements. One of the reasons is the missing integration of the technical architecture, organizational infrastructure and cultural aspects, besides the financial components [43].

An example is Company E (retail bank) that acquired another bank in Eastern Europe. The goal was to integrate the new company on the organizational and the technical side as well as possible. The chosen method of IT integration was a mix between a standardization and coexistence approach [44]. Company E already had negative experiences with failed standardizations and this time took the approach to standardize some processes where possible but still kept two co-existing systems. The EAM department in this case took a consulting role and provided experiences from past projects. Thus, the transformation is considered a success as of today.

Another scenario often mentioned by the architects is the replacement of information technology or legacy systems. These are replaced for several reasons rooted either in the business or the IT side of the enterprise [45]. On the business side, typical causes are for example: "Changes in accounting practices and policies", "financial drivers", i.e. in terms of productivity, "requirement of new system capabilities" and many more [45]. The technical side can also provide reasons for a replacement: "System not compatible with newer technologies", "costs of upgrading are too high", "technology that is no longer supported" or that the necessary staff is unique and expensive [45]. Often the cost driver is and most of the technical problems arise from a lack of documentation in the legacy systems [46]. The replacement of technical components is often accompanied by large transformations in other areas of the organization, such as personal or cultural changes. However, in such large scale transfor- 
mations a significant degree in planning is necessary in order to prevent disruption of the operational business [47]. This is important because in most cases, such transformations fail because of their complexity and changing business objectives [48].

An example for this scenario is Company $\mathrm{H}$. The transformation project conducted established a new access and identity management (AIM) system. An AIM system is used to control the responsibilities and permissions of the employees in the different applications and databases. The scope of this transformation is enterprise-wide, since it affects every user. The driver for this project was not primarily cost reduction or the replacement of an old mainframe system but to meet regulatory requirements.

The third major scenario that we identified during the study is the consolidation of systems. While it is similar to the previous scenario, the difference is the focus on consolidation of small systems rather than replacing core legacy systems. Companies introduce massive transformation initiatives to reduce the number of applications. Typical processes are to research what kinds of applications are necessary to carry out the different business processes [49]. Afterwards, obsolete systems are discovered and eliminated. However in general the goals are similar to the replacement of IS: cutting costs and reducing complexity, which results in a more competitive IS structure.

As an example, Company D is a global developer and manufacturer of consumer goods. Their strategic goal is to conduct a transformation from a production based company to a consumer driven company. This transformation has an effect on the IS landscape as well. Some years ago they started a huge initiative to introduce an ERP system for the finance and sales department. The most important reason, for not introducing this system for all departments was the fear of failure of a too large program. The area of customer service was, for example, not part of this ERP initiative. The customer service is mainly based on in-house-developed systems for each region. The problem is that the system and the knowledge holding employees are too old. The different systems produce costs and are difficult to maintain in the global data center. The goal is to bring all regions into one system, with some exceptions allowed. Additionally, the compatibility with the new ERP system must be ensured.

The other cases are further business oriented transformations like business process reengineering or the development of a new business model.

Proposition 1: Most ETs that would benefit from EAM occur in the areas of mergers and acquisitions, replacement of IT, consolidation of systems and further businessrelated ones.

\subsection{EAM Activities of Transformation Support}

At first we were interested in activities that architects conduct in order to support ETs. Very often EAM has a moderator role and tries to bring different partners together. Like our informant from Company $\mathrm{G}$ stated: 
"We try to bring all the princedoms together at one table in order to figure out, which solution makes sense. If no agreement is possible the head of architecture or IT Manager decides - but that is always the last resort, because than it's not jointly supported by all participants" (Company G).

The business support for a transformation can be even more direct; EAM here can take the role of an internal intelligence service. While in certain transformations architects are members of the governance boards, in other cases EAM acts rather as a decision supporter. Our informant from Company D provides an example from a business model affecting transformation:

"If the e.g. business would like to reduce prices for certain spare parts and redefines a strategy according to which in order to foster a stronger customer commitment, we try to structure the relevant information by using questionnaires and catalogues" (Company D).

In the case of Company $\mathrm{F}$, the holistic character of EAM becomes evident. Here the task of EAM is having the overview of the manifold programs, projects and demands that are currently affecting the company. Further, the EAM department is the one, were all the target states are known and interferences easily can be identified. The informant from Company B further considers a globally understood EA method as a helpful means in order to support transformations, especially to have a common understanding of certain techniques and thus increase the probability of consistent outcomes. EA also helps to utilize external providers by identifying necessary capabilities that these must provide (Company $\mathrm{C}$ ).

If the architects are located in the IT department and are rather dealing with IT issues, further mechanisms become apparent. A major one is providing IT-related decision information to the transformation management team. But the job is not about information provision only - EAM is valuable for the CIO to communicate the IT part of the transformation and to strengthen his role. Our informant from Company $\mathrm{C}$ pointed out:

"If you consider which artifacts, results or intermediate results the CIO needs in order to communicate further up, e.g. to the CFO in order to allow for information about how well the IT support for certain business functions is." (Company C).

The results show that the term EAM covers two different areas of activity: On the one hand the planning and strategy about IT related issues (e.g. application landscapes) on the other hand rather qualitative additions to the overall transformation initiative - not necessarily about IT-related issues. This finding is in line with other studies like [50], thus we summarize: 
Proposition 2: The term EAM covers two related but different approaches of transformation support - one focusing on business/IT alignment and one rather oriented towards pure business issues.

\subsection{Means to Support Enterprise Transformations}

Even if from our perception, architects like to talk about the rather abstract mechanisms like described above, EAM is able to provide some very concrete means to support the transformation. Our participant from Company A outlines that it is very important to provide concrete advice and not being too theoretical.

Traditionally, EAM is very keen on planning target states, that are expressed e.g. in target process maps, target capability maps or application landscapes [31]. Another very important means are standards. However, standards can occur in very different shades. Traditionally standards are defined concerning applications or other specific EA artifacts. An artifact that supports the standardization of business-related aspects and helps to avoid misunderstandings during a transformation is a common language. Here the concept of logic object models is seen as a valuable means (Company B):

"If I ask five people, I get ten opinions about the used terms. That is, why we try to identify a common language at the moment, our means for that is the logic object model." (Company B)

However, since such standards are hard or sometimes even impossible to establish due to manifold reasons, some organizations rather standardize their methods than their results. In the case of Company $\mathrm{E}$ this increased the success of the transformation initiatives:

"In the past we had the strategy to introduce one certain system for the whole company. However, that did not work due to manifold requirements in the single national units. Thus, now we are rather working with standardized methods and concepts instead of concrete systems that we standardize".

Another means is the standardization of governance processes and thus the establishment of transformation-relevant boards and committees - enriched by additional discussions with specific stakeholders in IT and business away from the regular meetings (Company I).

Again, it is important that the architects are directly involved in the partial transformation projects and provide the necessary guidance. A means that architects seem to be very capable to provide is methodological guidance:

"We had multiple phases where a target organization was defined and it was clearly defined on a roadmap, when which organization should be transformed. We supported this with the architecture, mostly by providing methodological guidance" (Company E). 
Artifacts that were further mentioned pretty often are application landscapes or capability maps. Thus summarized:

Proposition 3: Artifacts that are very often used to support transformations are standards, roadmaps, capability maps or application landscapes.

\subsection{Establishing Transformational EAM}

While EAM is a well-established to support business-IT alignment, its establishment as an ET supporting discipline needs further efforts. Therefore, we discussed with the participants of our study about success factors of transformational EAM.

Overall the business side needs to trust in EAM and needs to consider the architects as appropriate to talk to (Company F). How can this be achieved? One major point is communicating in a way that the partner from the business side is directly able to understand. This means to use language and tools that are well-known on the business side. The experiences from Company $\mathrm{G}$ and Company I reflect this experience:

"I do no longer describe solutions with component- or flow-charts. I take the most important from the solutions that architects' draw and invest more time in communicating those extracts with the management. My goal is not to get a great picture of the architecture but having slides that help to convince the management - based on arguments, figures and cost-ratios." (Company G)

"We need to find the right tools in order to communicate with the business side. We used many tools that worked well for IT matters, but were not understood by the business. As an example: We have a domain model that aggregates our applications in a business-related manner. [...] That all worked very well for IT purposes but the business never really understood the model." (Company I)

Thus, the transformational EAM does not only draw architecture maps but goes the extra mile to already interpret and translate them into the relevant information that business departments need. It seems a good idea to concentrate on a few EA artifacts and provide these in a value-adding way instead of offering to much at the same time (Company D). These key artifacts are different in each enterprise and need to be identified by analysis and discussions. When such artifacts are in place, architects are needed, that are able to communicate also with top-management stakeholders.

"You need people who are able to communicate with the higher topmanagement. You need to know that these managers provide only brief meetings and you need to be able to hit the bottom line within this time." (Company C) 
Furthermore, EAM needs to be explained to other stakeholders during the transformation. These are project managers or other involved employees. Since EAM in many cases is not able to put pressure on the stakeholders, it needs to convince them:

"I am 80\% of my time in meetings [...]. We are not like kings that put thumbs up or down but instead discuss appropriate solutions with experts or stakeholders." (Company G)

"In general people are no fools, they are not more chuckleheaded than others." (Company B)

It is especially necessary to be able to explain the use on the local level - and not just what it means for the whole. That also includes to leave certain degrees of freedom on the local level and not to think that a central function can manage everything better.

"It's important to discuss what really needs to be synchronized. Do I really have to work in the same way everywhere? Or, where is the lowest common denominator? Where actually is it? That is the important point one has to think about and which you have to focus on afterwards." (Company B)

The experience of our informants shows that it is very valuable to be involved early in the projects and help to bring the necessary experts together or ensure that standards are kept. After that step, the architecture efforts can become lower and "people can do their work" (Company H). EAM usually can provide methodological guidance and best practices, especially in the beginning of projects - even if that often requires serious convincing efforts (Company D).

Proposition 4: In order to establish an EAM that supports transformations, communication and a focus on key artifacts is necessary.

\subsection{Pitfalls in ET Support by EAM}

In the interviews with our informants, we could identify three major pitfalls that challenge architects when ET support is important. The first major point are cultural issues. Especially in global transformations these become very important like many informants mention:

"We tried it at a foreign location, Japan. We tried to translate it in the language of the colleagues over there; we even provided the process as a Manga comic. [...] However, let's say, it was read ..." (Company B)

"I think that is a tendency in Germany. We are all artists. We want to have as much freedom as possible. When I do process management or use methods I reduce that freedom. [...] That does not comply with our culture and our feeling. " (Company B) 
"If they [Chinese locations] are starting to introduce a central ERP system for their location at a certain point of time, they have a look at how it was done in Germany or the US. [...] But, they are not that far when it comes to establishing the transparency that we do here - that's also about the mentality." (Company $C$ )

The second critical point is the measurement of transformation success. Success measurement is very often perceived as a difficult job and often not conducted at all. Similar to others, our informant in Company B reflects:

"If I introduce a software system it is easy to measure, e.g. by how often someone logs on. With a process change that is not possible" (Company B)

However, in the end the transformation efforts need to prove their success. While some prefer trying to establish financial figures since these are well established in the management, others focus on qualitative measurements:

"We are in contact with market research companies that provide information about the brand perception of our customers. Our success was measured by the feedback of our consumers" (Company D).

The third important pitfall is EA's tendency to become an end in itself or not to consider the question of how much EAM is enough. The informants almost agreed upon the fact that EAM for transformations needs to set the overall frame but should not become too detailed.

"I think it [EAM] should provide the rough frame and processes. Very brought, not in detail - since the details change too often" (Company B).

"That is the problem. Many architects prefer to work very clean. Build clear architectures, start by the low layers. However, they forget that this does not create a business value. Finding the right balance is important" (Company I).

Proposition 5: Pitfalls that need to be avoided are disregarding cultural issues, inadequate success measurement and an EAM that becomes an end in itself.

\subsection{The Future of Transformational EAM}

During the discussions some implications came up on how EAM will or should develop in the future as a transformation supporting discipline. So far, EAM is usually considered as an IT matter [31] - which in itself is not a problem since IT nowadays is a major part of many transformations, especially in industries like insurance or banking: 
"IT is the shop floor of the bank. Where other industries have their factories to produce their products we have the IT to fulfill the task."

(Company I).

According to our informants, EAM is able to provide a view on the global IT possibilities and allows for further information about existing processes or applications (Company C). The job of business-IT alignment will become more and more ensured without further efforts, while new business requirements are implemented (Company F). IT can even be the pioneer concerning transformation experiences (Company C). The reason is that in the IT area transformations like outsourcing [51] are conducted often at the moment. Other areas will follow and experiences made once can be used.

Overall an evolution of EAM towards a more business-centric transformation supporting discipline can be recognized but requires additional efforts and fosters new challenges. This already starts with wording issues. While the term "enterprise architecture" is considered to be a very technical term [12] and thus will change, e.g. to "enterprise transformation management" (Company F). The whole process will take time (comparable to the establishment of process management as a single discipline in enterprises) (Company B). EAM needs not to be established as a single department but rather should be in the minds of the company's kind of organizational intelligence (Company B).

Furthermore, the trend seems to be a shift from documentation towards governance [11] as a main EAM task:

"During the last three years we moved away from documentation to governance. During restructuration last year, we moved from the development department to a specific governance and compliance department. Because of that we got more visible recently." (Company $H$ )

In parallel to the shift in tasks, many EAM departments strive after more business orientation. While this is a very well-known trend [50] one of the informants claimed that EAM needs to be careful of not to lose its connection to the IT:

"If we use too many IT terms that could cause denial at the business side. But, if we use too much business language, our influence within our own organization [IT] will slowly diminish, which means, the acceptance could diminish”. (Company D)

Thus, the future of EAM as a transformation supporting discipline stays multifaceted and manifold development pathways are thinkable. Summarized:

Proposition 6: EAM as a transformation discipline will move away from a pure documentation of IT-related matters but architects need to be careful, not to lose the focus with its respective stakeholders. 


\section{Discussion}

EAM is often involved in ETs and contributes in a valuable way. However, there seems not to be one possible way for EAM's contribution. We explored the perspective of the architects on ETs and collected their practices and experiences. In Table 3 we summarize the propositions we derived within the findings section.

Table 3. Propositions Summary

\begin{tabular}{ll}
\hline & Proposition \\
\hline 1 & $\begin{array}{l}\text { Most ETs that would benefit from EAM occur in the areas of mergers and acquisi- } \\
\text { tions, replacement of IT, consolidation of systems and further business-related ones. }\end{array}$ \\
\hline 2 & $\begin{array}{l}\text { The term EAM covers two related but different approaches of transformation support } \\
\text { - one focusing on business/IT alignment and one rather oriented towards pure business } \\
\text { issues. }\end{array}$ \\
\hline 3 & $\begin{array}{l}\text { Artifacts that are very often used to support transformations are standards, roadmaps, } \\
\text { capability maps or application landscapes. }\end{array}$ \\
\hline 4 & $\begin{array}{l}\text { In order to establish an EAM that supports transformations, communication and a } \\
\text { focus on key artifacts is necessary. }\end{array}$ \\
\hline 5 & $\begin{array}{l}\text { Pitfalls that need to be avoided are disregarding cultural issues, inadequate success } \\
\text { measurement and an EAM that becomes an end in itself. }\end{array}$ \\
\hline 6 & $\begin{array}{l}\text { EAM as a transformation discipline will move away from a pure documentation of IT- } \\
\text { related matters but architects need to be careful, not to lose the focus with its respec- } \\
\text { tive stakeholders. }\end{array}$ \\
\hline
\end{tabular}

The identified transformation scenarios show that defining scenarios is a lot depending on the perspective taken. While in our exploration IT-driven and business-driven scenarios are occurring almost half by half, other authors (e.g. [52, 53]) would not explicitly consider IT-driven scenarios as transformation but rather differentiate the business-driven scenarios more in detail.

The second proposition became very clear during the study - EAM covers many very different activities and tasks which foster serious problems on explaining, what the discipline actually does - this seems to be very different depending on the company talked to. Our impression is that we can find a "traditional" type of EAM that is very strongly rooted in the IT departments and deals with handling the IT complexity. These activities are very important in almost all transformations since IT is always affected. The role of these "traditional" architects however differs depending on the transformation scenario that occurs. While they can and should take a strong role in the IT-related scenarios (e.g. by providing detailed plans about IT dependencies), their transformation support might be more passive in the business-oriented ones. The other "extreme" that we find is the business-oriented EAM approach. This one often occurs in industries were IT is a major part of the value creation (banking, finance, etc.). It is also rooted in the IT but emancipated itself towards a more business-related position (and thus can contribute by providing dependencies between capabilities or 
within those). Architects who conduct this style of EAM are much more involved in strategic discussions or business related decisions than those dealing with pure IT issues.

However, proposition three shows that EAM has the potential to further establish itself as a discipline that supports the ET. When we compare the mentioned artifacts and provided services by current EAM with the theoretical potential based on the EAM meta-model (see figure 1 in the related work section), it becomes apparent that EAM could provide more guidance than it currently does in many cases. How could EAM emerge in that direction? Proposition four shows that the key lesson learned is fostering an appropriate communication and establishing a focus on key deliverables that are related to the transformation. Therefore, it seems to be better to concentrate on the provision of not too many but meaningful artifacts instead of being too broad or getting lost in the details.

In addition, major pitfalls need to be avoided. These are cultural issues - may those occur while applying certain EA standards in other countries or even subunits of the enterprise. Furthermore the goals and the success of transformations and EA use need to be measured - or at least regularly assessed on a qualitative basis. That is necessary especially to know what the demands are and not to become an end in itself. That goes along with proposition six, which includes the perception that EAM will more and more develop away from a discipline that mostly does documentation towards one that is involved and respected as a strategic advisor.

Our propositions should guide the development and design of new EAM approaches in the future. While we explored the perceptions of the architects about how EAM supports transformations, new EAM frameworks or design theories [54] could especially focus this point. Such approaches need to consider the role that the EAM department has within the concrete enterprise - is it supposed to add information about IT issues or is it able (and allowed) to add support to additional, more business and strategy related issues? Depending on the answer, EAM approaches would be different and would support different activities that are taken when managing transformations. We see great potentials for design oriented researchers to provide artifacts in this area.

\section{Summary \& Conclusion}

In the paper at hand we provided an empirical exploration about the EAM support of ETs. Based on interviews with highly knowledgeable informants from nine enterprises we explored the transformation support and potentials of EAM concerning this purpose. Our findings reveal IT-driven as much as business-driven scenarios of transformation were EAM can be effective. We further investigated what the major pitfalls are and how a transformational EAM in the future could look like.

Some limitations occur. We conducted a qualitative study based on a relatively small number of participating companies and interviews. However, we consider this very suitable for the given purpose of field exploration. Especially since we discussed with 
highly knowledgeable informants [33] the chosen method provides empirically sound propositions for further research [32]. Since the topic is complex, we were only able to cover a broad rather than a deep perspective in this paper. However, this broad perspective helps to develop more concrete research designs (e.g. qualitative questionnaires) or artifacts (e.g. EAM capabilities) in the future.

In consequence, we plan further research in the topic area. First, we need to gain clarity about the inputs that EAM can provide to the management of ET. Second, we need to understand, which kind of EAM is suitable for which ET scenario. Finally, such findings should be consolidated in an integrated approach, aiming at the architectural support of enterprise transformations.

\section{Acknowledgement:}

This work has been supported by the Swiss National Science Foundation.

\section{$7 \quad$ References}

1. Tamm, T., Seddon, P.B., Shanks, G., Reynolds, P.: How Does Enterprise Architecture Add Value to Organisations? Communications of the Association for Information Systems 28, 141-168 (2011)

2. Aier, S., Riege, C., Winter, R.: Unternehmensarchitektur - Literaturüberblick und Stand der Praxis. Wirtschaftsinformatik 50:4, 292-304 (2008)

3. Lahrmann, G., Labusch, N., Winter, R., Uhl, A.: Management of Large-Scale Transformation Programs: State of the Practice and Future Potential. In: Trends in Enterprise Architecture Research and Practice Driven Research on Enterprise Transformation, pp. 253-267. Springer, Barcelona (2012)

4. Rouse, W.B.: A Theory of Enterprise Transformation. Systems Engineering 8:4, 279-295 (2005)

5. Buchta, D., Eul, M., Schulte-Croonenberg, H.: Strategic IT Management - Increase value, control performance, reduce costs. Gabler, Wiesbaden (2007)

6. Abraham, R., Aier, S., Labusch, N.: Enterprise Architecture as a Means for Coordination An Empirical Study on Actual and Potential Practice. In: MCIS 2012 Proceedings, p. Paper 33. AIS Electronic Library, Guimarães (2012)

7. Malone, T.W., Crowston, K.: The Interdisciplinary Study of Coordination. ACM Computing Surveys 26:1, 87-119 (1994)

8. Lankhorst, M.: Enterprise Architecture at Work: Modelling, Communication and Analysis. Springer, Berlin, Heidelberg (2009)

9. Ross, J.W., Weill, P., Robertson, D.C.: Enterprise Architecture as Strategy. Creating a Foundation for Business Execution. Harvard Business School Press, Boston, MA (2006)

10. Pulkkinen, M., Naumenko, A., Luostarinen, K.: Managing information security in a business network of machinery maintenance services business - Enterprise architecture as a coordination tool. Journal of Systems and Software 80:10, 1607-1620 (2007)

11. Op't Land, M., Proper, E., Waage, M., Cloo, J., Steghuis, C.: Enterprise Architecture Creating Value by Informed Governance. Springer, Berlin (2009) 
12. Asfaw, T., Bada, A., Allario, F.: Enablers and Challenges in Using Enterprise Architecture Concepts to Drive Transformation: Perspectives from Private Organizations and Federal Government Agencies. Journal of Enterprise Architecture 5:3, 18-28 (2009)

13. Radeke, F.: Toward Understanding Enterprise Architecture Management's Role in Strategic Change: Antecedents, Processes, Outcomes. In: Wirtschaftinformatik Proceedings 2011. Paper 62. (2011)

14. Rouse, W.B., Baba, M.L.: Enterprise transformation. Communications of the ACM 49:7, 67-72 (2006)

15. Basole, R.C.: Transforming Enterprises through Mobile Applications: A Multi-Phase Framework. In: Proceedings of the Eleventh Americas Conference on Information Systems, Omaha, NE (2005)

16. Kotnour, T., Bollo, T.R.: Strategic management of a transformation in a multi-program technology program involving convergence and divergence of programs: Observations from NASA. International Journal of Technology Management 53, 257-272 (2011)

17. Uhl, A., Gollenia, L.A. (eds.): A Handbook of Business Transformation Management Methodology. Gower Publishing, Farnham, UK (2012)

18. Stiles, P., Uhl, A.: Meta Management: Connecting the Parts of Business Transformation. $360^{\circ}$ - The Business Transformation Journal:3, 24-29 (2012)

19. Winter, K., Buckl, S., Matthes, F., Schweda, C.M.: Investigating the State-of-the-Art in Enterprise Architecture Management Methods in Literature and Practice. In: MCIS 2010 Proceedings, p. Paper 90 (2010)

20. Buckl, S., Ernst, A.M., Lankes, J., Matthes, F., Schweda, C.M.: State of the Art in Enterprise Architecture Management 2009. (2009)

21. Matthes, F., Monahov, I., Schneider, A., Schulz, C.: EAM KPI Catalog v 1.0. Munich. Springer, Heidelberg (2012)

22. Bernard, S.A.: An Introduction to Enterprise Architecture: Second Edition. Authorhouse, Bloomington, IN (2005)

23. Foorthuis, R., van Steenbergen, M., Mushkudiani, N., Bruls, W., Brinkkemper, S., and Bos, R.: On Course, but Not There Yet: Enterprise Architecture Conformance and Benefits in Systems Development. In: ICIS 2010 Proceedings. Paper 110. (2010)

24. Ross, J.W., Weil, P.: Understanding the benefits of enterprise architecture. Cambridge, MA. Springer, Heidelberg (2005)

25. Boh, W.F., Yellin, D.: Using Enterprise Architecture Standards in Managing Information Technology. Journal of Management Information Systems 23:3, 163-207 (2007)

26. The Open Group: TOGAF Version 9.1 (2011)

27. Chen, Z., Pooley, R.: Requirement Analysis for Enterprise Information Systems Developing an Ontological Meta-Model for Zackman Framework. In: ICIS 2009 Proceedings, p. Paper 182, Phoenix, AZ (2009)

28. Department of Defense: DoD Architecture Framework Version 2.02. Springer, Heidelberg (2012)

29. Ifip-Ifac Task Force on Architectures for Enterprise Integration: GERAM - The Generalised Enterprise Reference Architecture and Methodology. In: Bernus, P., Nemes, L., Schmidt, G. (eds.): Handbook on Enterprise Architecture, pp. 22-63. Springer, Berlin (2003)

30. Labusch, N., Winter, R.: Towards a Conceptualization of Architectural Support for Enterprise Transformation. In: Proceedings of the European Conference on Information Systems (ECIS) 2013, Utrecht, NL (2013) 
31. Winter, R., Townson, S., Uhl, A., Labusch, N., Noack, J.: Enterprise Architecture and Business Transformation: The Difference and Synergy Potential. $360^{\circ}$ - The Business Transformation Journal, (2012)

32. Eisenhardt, K.M.: Building Theories from Case Study Research. Academy of Management Review 14:4, 532-550 (1989)

33. Eisenhardt, K.M., Graebner, M.E.: Theory Building from Cases: Opportunities and Challenges. Academy of Management Journal 50:1, 25-32 (2007)

34. vom Brocke, J., Simons, A., Niehaves, B., Riemer, K., Plattfaut, R., Cleven, A.: Reconstructing the Giant: On the Importance of Rigour in Documenting the Literature Search Process. In: Proceedings of the ECIS 2009, pp. 2206-2217, Verona (2009)

35. Webster, J., Watson, R.T.: Analyzing the Past to prepare for the Future: Writing a Literature Review. MIS Quarterly 26:2, 13-23 (2002)

36. Schrader, U., Hennig-Thurau, T.: VHB-JOURQUAL2: Method, Results, and Implications of the German Academic Association for Business Research's Journal Ranking. BuR Business Research 2:2, 180-204 (2009)

37. Labusch, N., Winter, R.: Method Support of Large-Scale Transformation in the Insurance Sector: Exploring Foundations. In: Trends in Enterprise Architecture Research and Practice Driven Research on Enterprise Transformation, pp. 60-78. Springer, Barcelona (2012)

38. Burke, L.A., Miller, M.K.: Phone Interviewing as a Means of Data Collection: Lessons Learned and Practical Recommendations. Forum: Qualitative Social Research 2:2, 1-8 (2001)

39. Jick, T.D.: Mixing Qualitative and Quantitative Methods: Triangulation in Action. Administrative Science Quarterly 24:4, 602-611 (1979)

40. Huber, G.P., Power, D.J.: Retrospective reports of strategic-level managers: Guidelines for increasing their accuracy. Strategic Management Journal 6:2, 171-180 (1985)

41. Bailey, K.D.: Typologies and Taxonomies: An Introduction to Classification Techniques. Sage University Papers Sage Publications, Thousand Oaks (1994)

42. Koch, T.: Post-Merger Integration. In: Picot, G. (ed.): Handbook of International Mergers and Acquisitions: Preparation, Implementation and Integration, pp. 271-291. Palgrave McMillan, New York (2002)

43. Robbins, S.S., Stylianou, A.C.: Post-merger systems integration: the impact on IS capabilities. Information \& Management 36:4, 205-212 (1999)

44. Wijnhoven, F., Spil, T., Stegwee, R., Fa, R.T.A.: Post-merger IT integration strategies: an IT alignment perspective. The Journal of Strategic Information Systems 15:1, 5-28 (2006)

45. Devine, T.: Replacing a Legacy System. (2008)

46. Bisbal, J., Lawless, D., Bing, W., Grimson, J., Wade, V., Richardson, R., O'Sullivan, D.: An overview of legacy information system migration. In: Proceedings of the Asia Pacific Software Engineering Conference and International Computer Science Conference (APSEC '97 and ICSC '97), pp. 529 - 530 (1997)

47. Sneed, H.M.: Planning the reengineering of legacy systems. IEEE Software 12:1, 24-34 (1995)

48. Seacord, R.C., Plakosh, D., Lewis, G.A.: Modernizing Legacy Systems: Software Technologies, Engineering Processes, and Business Practices. Addison-Wesley Longman, Amsterdam (2003)

49. Comella-Dorda, S., Wallnau, K., Seacord, R., Robert, J.: A Survey of Black-Box Modernization Approaches for Information Systems. In: Proceedings of the 16th IEEE International Conference on Software Maintenance, pp. 173-183 (2000)

50. Blosch, M., Burton, B.: Enterprise Architecture Leaders Focus on Business Impact. (2012) 
51. Lacity, M.C., Khan, S.A., Willcocks, L.P.: A review of the IT outsourcing literature: Insights for practice. The Journal of Strategic Information Systems 18:3, 130-146 (2009)

52. Baumöl, U.: Change Management in Organisationen: Situative Methodenkonstruktion für flexible Veränderungsprozesse. Gabler, Wiesbaden (2008)

53. Baumöl, U.: Strategic Agility through Situational Method Construction. In: Proceedings of the European Academy of Management Annual Conference 2005, München (2005)

54. Gregor, S., Jones, D.: The Anatomy of a Design Theory. Journal of the Association for Information Systems 8:5, 312-335 (2007) 